\title{
Complete Resolution of Wegener's Granulomatosis Lung Granuloma After Aortic Root Replacement
}

\author{
Sarah-Jayne Edmondson, MRCS*, Saina Attaran, MD, Ulrich P. Rosendahl, MD \\ Royal Brompton Hospital NHS Foundation Trust, Department of Cardiothoracic Surgery, London, UK
}

\begin{abstract}
Wegner's granulomatosis (WG) is an autoimmune systemic vasculitis that results in necrotizing granulomas. We report a WG patient with a lung granuloma and aortic root dilatation, who underwent aortic root replacement on cardiopulmonary bypass (CPB). Intraoperatively, the patient suffered an aortic dissection, which was repaired immediately under deep hypothermic circulatory arrest (DHCA). Follow-up imaging showed complete granuloma resolution, despite absence of immunosuppressive therapy. Immune stimulation following CPB is well described; here, the opposite was observed and DHCA effects are discussed.

Copyright $\odot 2016$ Science International Corp.
\end{abstract}

\section{Key Words:}

Aortic root - Dissection - Inflammation - Wegener's granulomatosis

\section{Introduction}

Wegener's granulomatosis (WG) is an autoimmune systemic vasculitis, of unknown etiology, classically affecting small-to-medium-sized vessels and characterized by necrotizing granulomas. It most commonly affects the respiratory and renal systems; however, cardiac involvement is not uncommon (up to $44 \%$ of cases), with the most common clinical presentations being pericarditis, supraventricular arrhythmias, and heart block [1]. Although the exact etiology of inflammation in WG is unclear, lesions are thought

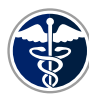

Fax +1 2037853552

E-Mail: aorta@scienceinternational.org

http://aorta.scienceinternational.org

\author{
(c) 2016 AORTA \\ Published by Science International Corp. \\ ISSN 2325-4637 \\ Accessible online at: \\ http://aorta.scienceinternational.org
}

to be initiated by T-cells, which cross-react with auto-antigens in vessel walls, overproducing factors such as tumor necrosis factor alpha (TNFa) [2]. These cells then activate macrophages and upregulate the production of pro-inflammatory cytokines [2], advancing WG inflammation. Treatment is therefore focused on inhibiting pro-inflammatory pathways with cyclophosphamide (which acts through its metabolite, phosphoramide mustard, forming irreversible DNA crosslinks both between and within DNA strands at guanine N-7 positions and leading to enhanced cell apoptosis and depletion of T-lymphocytes); or, in resistant cases, monoclonal antibodies (causing TNFa blockade) [3].

We report a case of a patient with WG requiring cardiac surgery who had a surprising response to the effects of cardiopulmonary bypass (CPB), which is well known to cause a significantly augmented increase of most humoral parameters of inflammation [4].

\section{Case Presentation}

A 63-year-old female was diagnosed with WG following an investigation of hemoptysis, revealing three respiratory necrotising granulomas in her left lower lobe. Despite immunosuppresant and steroid treatment [pulsed Intravenous cyclophosphamide (15 mg/kg) and prednisolone ( $1 \mathrm{mg} / \mathrm{kg} /$ day), respectively], the lesions increased in size, necessitating granuloma and, hence, left lower lobe resection. Histology showed features

*Corresponding Author:

Sarah-Jayne Edmondson, MRCS

Department of Cardiothoracic Surgery

Royal Brompton Hospital

Sydney Street, London SW3 6NP, UK

Tel: +44 7540 841451; Fax: +44 207349 7749; E-Mail: sarah-jayne.edmondson@nhs.net 
characteristic of Wegener's disease, including a pauci-immune leukocytoclastic vasculitis with necrotizing granulomatous inflammation. Remission was achieved. Following cessation of maintanence immunosuppressive therapy, 20 months following her initial diagnosis, she remained under regular review.

Three years after her initial diagnosis, a survillence computed tomography (CT) scan of her chest showed a cavitating mass $(29 \mathrm{~mm} \times 39 \mathrm{~mm})$ in the mid-zone of the left lung (Figure 1A), highly suspicious of a new granulomatous lesion. Differential diagnosis of infective or neoplastic causes were actively excluded, and serology (ANCA), imaging, and clinical features confirmed WG. Incidently, a significantly dilated aortic root was also noted, with the following measurements: sinus of Valsalva, $56 \mathrm{~mm}$; sinotubular junction, $51 \mathrm{~mm}$; and, ascending aorta, $41 \mathrm{~mm}$ (Figure 1B).

The patient was referred to our department for aortic root replacement. Following a multidisciplinary team discussion, it was determined that surgery should be expedited prior to commencing immunosuppressive treatment, as the anticipated, and well described, significantly increased immune response seen during CPB in combination with immunosupressive therapy would have put the patient at a greater risk of an adverse outcome and rapid disease progression. In view of her significant family history of two sisters who also suffered from aortic dilatations and, in one case, rupture, the patient was additionally referred for genetic testing. No mutations were identified in the fibrillin-1 gene, excluding Marfan's as a possible factor in dilatation.

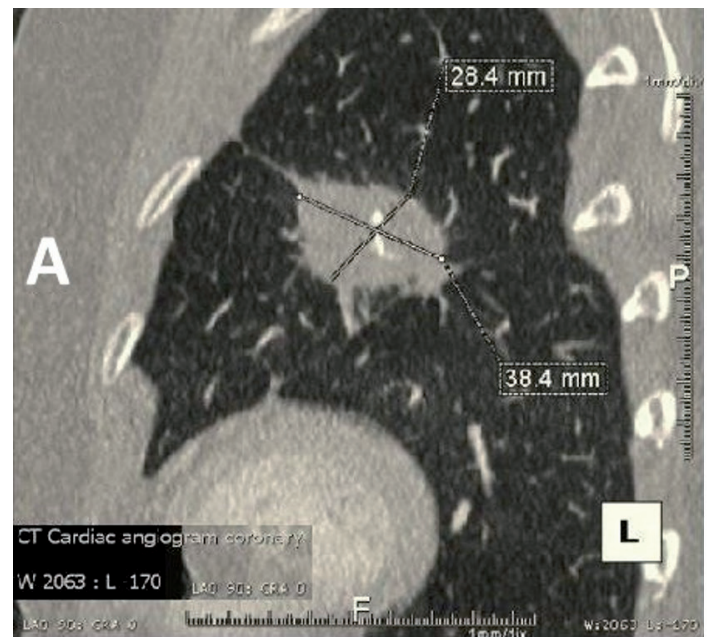

Figure 1. Panel A. Computerized tomography $(C T)$ confirming new lung granuloma with the typical vascularized necrotic core seen

in Wegener's granulomatosis lesions. Panel B. CT showing dilated aortic root.

AORTA, February 2016

After median sternotomy and heparinization, CPB was initiated. While cannulating the aorta, the patient suffered an acute Type A aortic dissection (DeBakey I). This was noted immediately, and the ascending aorta was replaced with a $30-\mathrm{mm}$ Hemashield vascular graft (Atrium, USA) under deep hypothermic circulatory arrest (DHCA) $\left(22^{\circ} \mathrm{C}\right.$ body temperature). The aortic root was replaced with a 29-mm stentless bioprosthetic root (Freestyle, Medtronic, Minneapolis, Minnesota, USA) with coronary reimplantation.

The patient made a full recovery postoperatively. Histology of the ascending aorta showed intimal fibrosis but no cystic medial degeneration or aortitis. CT of the chest 1 week postoperatively revealed an almost complete resolution of the lung granuloma despite no interim immunosuppressive therapy (Figure 2). Serial CT scans up to 6 months postoperatively demonstrated no ressurgence of the lung granuloma. We also noted that besides a residual epiaortic hematoma, there was no evidence of previous dissection, with no persisting false lumen.

\section{Discussion}

The significantly increased immune response during CPB is thought to be due to systemic endotoxemia, following exposure to the bypass circuit, stimulating pro-inflammatory cytokines and TNFa release, and causing T-cell activation [4]. As previously discussed, such T-cells are thought to be the

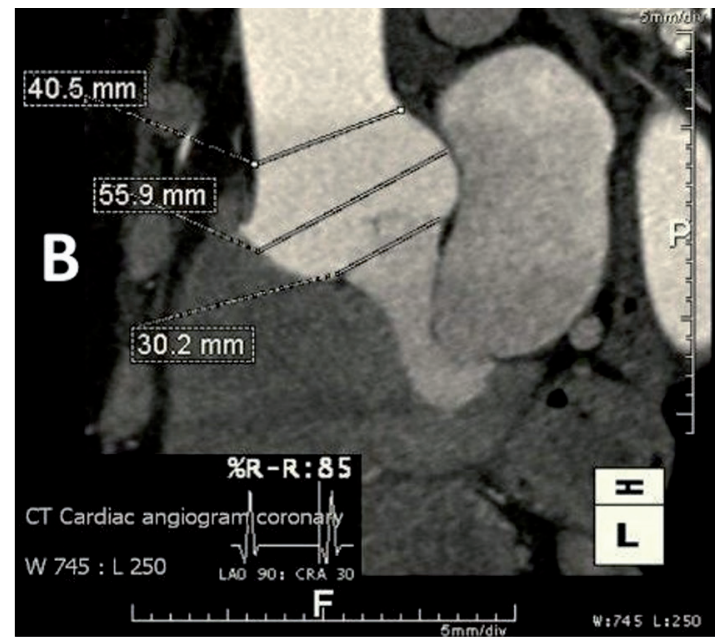

Volume 4, Issue 1:25-28 


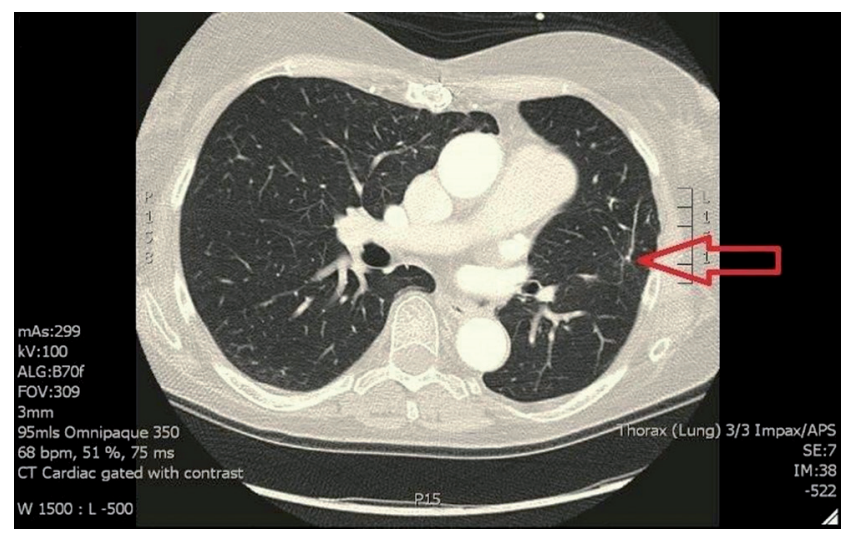

Figure 2. Computerized tomography 6 months postoperatively. Almost complete resolution of the previous granuloma is seen with only small atelectasis/calcification left behind.

main initiators and propagators of WG [2]. Therefore, deterioration of WG, and other auto-immune conditions, is anticipated in patients undergoing CPB due to this increased immune response. However, in this case, the opposite occurred, and, to our knowledge, this is the first time such a case has been reported in the literature.

Studies have now shown, however, that a physiologically balanced anti-inflammatory response also occurs during $C P B$, through parallel increases in IL-10: a potent anti-inflammatory cytokine that suppresses T-cell activity by downregulating certain immune pathways [4]. A degree of balance in immune response to CPB may imply that WG lesions should, if not deteriorate, remain unchanged. However, IL-10 has also been found in increased circulating levels in patients during DHCA [5], which has been suggested to be the reason for significant, post-DHCA immunosuppression [5]. Studies into novel WG treatments have suggested that IL-10 may be effective in achieving WG resolution [2]. Therefore, an explanation for granuloma resolution in this case could be that the CPB pro-/anti-inflammatory balance was tipped toward immunosuppression via increased IL-10 levels during, and post, DHCA. The resolution may also have been aided by decreased TNFa levels, as another study has shown diminished mRNA levels for TNFa post-CPB [6]. This finding suggests a highly significant reduction in pro-inflammatory cytokine biosynthesis and TNFa synthesis in the immediate post-CPB period [6]. We speculate from our observations that there is a possibility that if
DHCA stimulates granuloma remission, there is a possibility that it could also promote malignant tumor remission; however, no studies to date have confirmed this.

Aside from granuloma resolution, the cause of aortic dilatation is unclear. Although WG primarily affects small-to-medium-sized vessels, there are reports of large-vessel, such as subclavian artery, aneurysms occurring [7]. Histology from the ascending aorta did not show WG pathognomonic changes; however, it did show intimal fibrosis, which is seen initially as part of WG changes. We wonder if the findings represent early WG cardiovascular changes, which, when combined with an unaccounted genetic predisposition, may lead to the development of a dilated root.

In addition, this case emphasises that immediate/ very early recognition and repair of intraoperative, retrograde acute aortic dissection can result in the complete restoration of the aortic wall without a residual false lumen, which usually persists after Type A repair. A patent false lumen is associated with increased late mortality and morbidity due to progressive aneurysmal false-lumen dilatation, occurring in approximately one-fifth of cases. The thinner outer wall confers an increased rupture and hence mortality risk [8]. Therefore, in this patient with an unexplained genetic predisposition to large-vessel aneurysms, we predict that repair will provide a reduced risk of further aneurysmal development and/or rupture.

In conclusion, this case demonstrates the need for further investigations into the pathophysiology of tumor tissue and the immune system under the circumstances of CPB and DHCA. The immediate complete resolution of a WG lesion after CPB with DHCA suggests a cause-effect relationship-and ample potential molecular pathways for such an effect can be called to bear.

\section{Conflict of Interest}

The authors have no conflicts of interest relevant to this publication.

\section{Comment on this Article or Ask a Question}




\section{References}

1. Grant SC, Levy RD, Venning MC, Ward C, Brooks NH. Wegener's granulomatosis and the heart. Br Heart J. 1994;71:82-86. DOI: 10.1136/hrt.71.1.82

2. Lúdvíksson BR, Sneller MC, Chua KS, Talar-Williams C, Langford CA, Ehrhardt $\mathrm{RO}$, et al. Active Wegener's granulomatosis is associated with HLA-DR+ CD4+ T cells exhibiting an unbalanced Th1-type $T$ cell cytokine pattern: Reversal with IL-10. J Immunol. 1998;160:3602-3609. PMID: 9531324

3. Lutsiak ME, Semnani RT, De Pascalis $\mathrm{R}$, Kashmiri SV, Schlom J, Sabzevari H. Inhibition of $\mathrm{CD} 4+25+\mathrm{T}$ regulatory cell function implicated in enhanced immune response by low-dose cyclophosphamide. Blood. 2005;105:2862-2868. DOI: 10.1182/ blood-2004-06-2410

4. Diegeler A, Doll N, RauchT, Haberer D, Walther $T$, Falk V, et al. Humoral immune response during coronary artery bypass grafting. A comparison of limited approach, "off-pump" technique, and conventional cardiopulmonary bypass. Circulation. 2000;102:95-100. DOI: 10.1161/01.CIR.102.suppl_3.III-95

5. Stewart CR, Landseadel JP, Gurka MJ, Fairchild KD. Hypothermia increases interleukin-6 and interleukin-10 in juvenile endotoxemic mice. Pediatr Crit Care Med. 2010;11:109-116. DOI: 10.1097/ PCC.0b013e3181b01042

6. Börgermann J, Friedrich I, Flohé $S$, Spillner J, Majetschak M, Kuss O, et al. Tumor necrosis factor-a production in whole blood after cardiopulmonary bypass: Downregulation caused by circulating cytokine-inhibitory activities. J Thorac Cardiovas Surg. 2002;124: 608-617. DOI: $10.1067 / \mathrm{mtc} .2002 .122300$

7. Shitrit $D$, Shitrit $A B$, Starobin $D$, Izbicki $G$, Belenky A, Kaufman N, et al. Large vessel aneurysms in Wegener's granulomatosis. J Vasc Surg. 2002;36:856-858. DOI: 10.1067/mva.2002.126088

8. Ergin MA, Phillips RA, Galla JD, Lansman SL, MendelsonDS, QuintanaCS, etal. Significance of distal false lumen after type A dissection repair. Ann Thorac Surg. 1994;57:820-824. DOI: 10.1016/0003-4975(94)90182-1

Cite this article as: Edmondson S-J, Attaran S, Rosendahl UP. Complete Resolution ofWegener's Granulomatosis Lung Granuloma After Aortic Root Replacement. AORTA (Stamford). 2016;4(1):25-28. DOI: http://dx.doi. org/10.12945/j.aorta.2015.15.009 